\title{
Tool Temperature and Process Modeling of Friction Stir Welding
}

\author{
Takashi Nakamura1,2*, Toshiyuki Obikawa ${ }^{3}$, Eitaro Yukutake ${ }^{4}$, Satoru Ueda ${ }^{4}$, Itaru Nishizaki1 \\ ${ }^{1}$ Public Works Research Institute, Tsukuba, Japan \\ ${ }^{2}$ The University of Tokyo, Tokyo, Japan \\ ${ }^{3}$ Tokyo Denki University, Tokyo, Japan \\ ${ }^{4}$ Industrial Technology Institute of Ibaraki Prefectural, Ibaraki, Japan \\ Email:^t-nakamura55@pwri.go.jp,obikawa@mail.dendai.ac.jp,nisizaki@pwri.go.jp
}

How to cite this paper: Nakamura, T., Obikawa, T., Yukutake, E., Ueda, S. and Nishizaki, I. (2018) Tool Temperature and Process Modeling of Friction Stir Welding. Modern Mechanical Engineering, 8, 78-94. https://doi.org/10.4236/mme.2018.81006

Received: December 27, 2017

Accepted: February 25, 2018

Published: February 28, 2018

Copyright ( $) 2018$ by authors and Scientific Research Publishing Inc. This work is licensed under the Creative Commons Attribution International License (CC BY 4.0).

http://creativecommons.org/licenses/by/4.0/

(c) (i) Open Access

\begin{abstract}
Friction stir welding (FSW) has many advantages rather than fusion welding, but details of internal phenomena during its processes have not yet been clarified. In this study, a thermo-mechanically coupled process model was developed to investigate FSW phenomena inside a tool and workpiece. As a workpiece, 6061-T6 aluminum alloy was employed. The system of FSW process model includes several thermal boundaries. Among heat flows through these boundaries, heat transfers into the exterior of the system become more sensitive to tool and workpiece temperatures than heat transfers within the system. This paper especially focused on a heat transfer coefficient at a workpiece bottom, and optimized it through experiments and finite element method (FEM) analyses. The tool temperatures during FSW were measured with a special tooling system with imbedded thermocouples within a tool. As a result, an analysis model that is able to investigate details at a wide range of traverse speeds was developed for practical high speed welding. Then, the accuracy of developed FEM model was validated with them. Finally, the temperatures and stress distribution around workpiece/tool interfaces were investigated with the developed model.
\end{abstract}

\section{Keywords}

Simulation Modeling, Parameter Optimization, Thermal Transfer Coefficient, Tool Temperature Measurement

\section{Introduction}

Friction stir welding (FSW) invented by the Welding Institute is a solid state joining technique initially intended to weld aluminum alloys [1]. Presently, it is 
used to weld many kinds of materials, such as aluminum, magnesium and titanium alloys and even plastics [2]. FSW welds materials in a solid state, so that it has many advantages over conventional liquid-solid welding methods: higher weld strength, fine grain size, low residual stress, no consumable materials and low energy input [3] [4]. This process consists of a rotating tool and plates or sheets to be welded, where the tool is plunged into the materials and traversed along a line to finish joining them. Despite the simple configuration, phenomena inside the materials under welding and at the interface between the rotating tool and materials are too complicated to fully understand because there is thermal softening of the materials and heat transmission between them at high temperatures.

It is of great importance to investigate these phenomena during FSW for sound joining of workpieces and high product qualities. Elucidation of the thermo-mechanical phenomena between tool and workpiece can lead to the optimization of welding parameters, effective tool design, and the application of FSW to new materials and products. For deep understanding of the FSW process, both experimental methods and numerical simulations can be adopted.

Welding parameters, material flows and tool/workpiece interface phenomena have direct influences on heat generation during FSW. Although much research has investigated the important aspect of welding phenomena based on temperatures measured at specific points of workpiece, only a few experimental studies have been reported about tool temperatures because very complicated settings are required for tool temperature measurements [5] [6] [7] [8] [9]. Accurate experimental data about tool surface temperature are necessary to understand exact temperatures at the tool/workpiece interface. They are also needed to precisely validate developed simulation models by comparing measured and calculated temperatures. Therefore, a method and device for effectively measuring tool temperatures are essential to investigate FSW processes from theoretical and practical viewpoints.

Temperature analyses of the tool and workpiece during FSW have been conducted in many research studies. One way to optimize the process is to utilize the thermo-mechanically coupled modeling of FSW, considering thermal boundaries and friction at tool/workpiece interfaces. Hence, numerical models to simulate many phenomena that occur inside the material and tool and at their interfaces have been increasingly required. However, it is very difficult to establish a model that exactly meets the experimental results over a wide range of FSW conditions. FSW models include some thermal boundaries, and temperatures of tool and workpiece are sensitive against heat flows through the boundaries, so that the optimum values of heat transfer coefficients are necessary for these thermal boundaries. However, almost no study has investigated the precise thermal boundary conditions for FSW modeling because relatively low traverse speeds have been adapted for the FSW simulations.

Relationships between process parameters, such as rotational and traverse 
speed, and inside temperatures are important information for production sites. Although some studies investigated the relationship between the traverse speed and FSW temperatures for aluminum alloys, they analyzed the temperatures at low traverse speed under around $3.5 \mathrm{~mm} / \mathrm{s}$ [10] [11]. For more practical use, simulation and experimental data at higher traverse speeds should be discussed.

In this study, a thermos-mechanically coupled process model was developed to investigate FSW phenomena inside a tool and workpiece and at their interface using the DEFORM-3D software. As a workpiece, 6061-T6 aluminum alloy was employed. The system of FSW process model includes several thermal boundaries. Among heat flows through these thermal boundaries, the heat transfers into the exterior of the system become more sensitive to tool and workpiece temperatures than the heat transfers within the system. This paper especially focused on a heat transfer coefficient at the workpiece bottom, and optimized it through experiments and finite element (FEM) analyses for a reasonable simulation model to be established. Although other FEM studies have investigated FSW process phenomena under low tool traverse speeds corresponding to laboratory scale experiments, this study developed an analysis model that is able to investigate material internal phenomena at a wide range of traverse speeds for practical high speed welding. Both as fundamental data and reference data for simulation modeling, the tool temperatures during FSW were measured with a special tooling system with imbedded thermocouples within a tool. Then, the heat transfer coefficient at the workpiece bottom was optimized and the accuracy of developed FEM model was validated. Finally, the temperatures and stress distribution around workpiece/tool interfaces were investigated with the developed simulation model.

\section{Procedure}

\subsection{Experiment to Investigate Tool Temperature and Welding Force}

Several experiments with 6061-T6 aluminum alloy were conducted to measure tool temperatures and welding forces while butt welding of the aluminum sheets. The obtained results served as the fundamental data to investigate FSW phenomena both inside the tool and workpiece and at their interface, and are used to develop an FEM analysis model which accurately represents internal phenomena around the tool/workpiece interface under a wide range of traverse speeds.

The experiments were conducted on a Hitachi Power Solution 2D-FSW machine and traverse and axial forces were measured with load cells equipped under the machine table. The geometry of each workpiece was $200 \mathrm{~mm}$ long, 70 $\mathrm{mm}$ wide and $4 \mathrm{~mm}$ thick and the sides of two workpieces were butt welded. The joining surfaces were machined previously to meet each other without small gaps. The tool had a shoulder $12 \mathrm{~mm}$ in diameter and $3^{\circ}$ in taper angle, and a threaded probe $6 \mathrm{~mm}$ in diameter and $3.8 \mathrm{~mm}$ in height.

With respect to welding temperature, tool side measurement was adopted be- 
cause tool temperatures are under nearly stable conditions during FSW process.

The tool inside temperatures during FSW were measured with MULTI

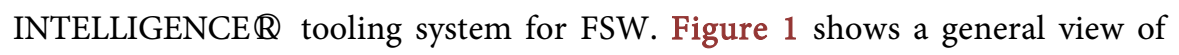
the temperature measuring tool used for experiments. Figure 2 shows the thermocouple positions imbedded in the tool. The thermo-couples were arranged at three different points to measure the temperatures of the probe-tip, probe-root and shoulder part respectively. The tool system was precisely assembled and thermo-couples were imbedded at positions around $1 \mathrm{~mm}$ from the tool surface to measure temperatures as close to tool/workpiece interface temperatures as possible.

Table 1 shows experiment conditions. To obtain data not only for fundamental

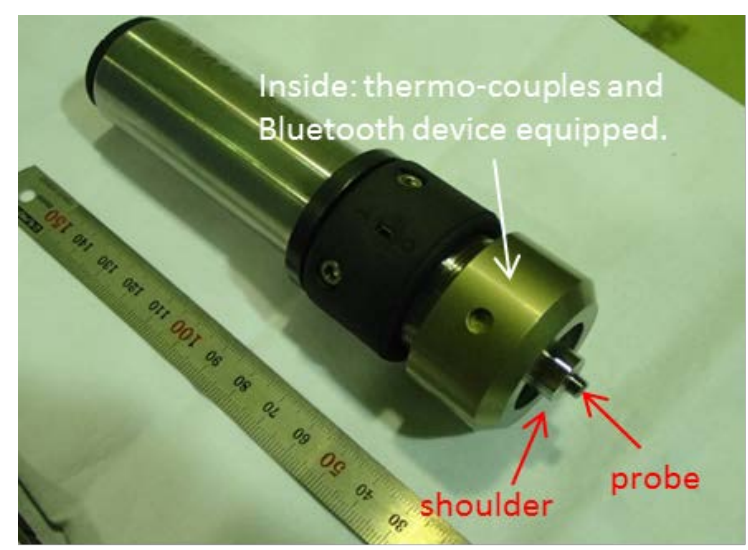

Figure 1. General view of temperature measuring tool.

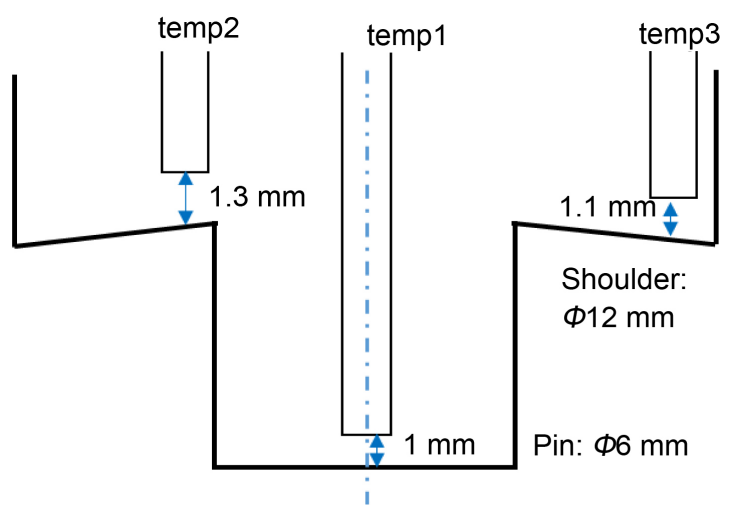

Figure 2. Cross-section view of positions for thermocouples imbedded in tool.

Table 1. Experiment conditions to measure temperatures and forces.

\begin{tabular}{cc} 
Tool & Alloy tool steel SKD61, Thread pin \\
Workpiece & $6061-\mathrm{T} 6$ \\
Workpiece geometry & $200 \times 70 \times 4 \mathrm{~mm}$ \\
Tool rotational speed $\left[\mathrm{min}^{-1}\right]$ & $750,1000,2000$ \\
Traverse speed $[\mathrm{mm} / \mathrm{s}]$ & $1,5,10,20$ \\
Tool advancing angle $[$ degree] & 3 \\
\hline
\end{tabular}


study but also for practical welding, traverse speeds were set for a wide range from $1 \mathrm{~mm} / \mathrm{s}$ to $20 \mathrm{~mm} / \mathrm{s}$, close to the practical traverse speed at production sites. In addition, the tool plunge speed was set to $0.5 \mathrm{~mm} / \mathrm{s}$, and then the tool was held for $5 \mathrm{~s}$ for the dwelling before traversing.

\subsection{FEM Simulation Modeling}

To clarify the thermal and mechanical phenomena of workpieces and tools during the FSW process, it is essential to understand temperature distributions, stress fields and strains inside tools and workpieces or at their interfaces. These inside and interface phenomena are difficult to investigate only by experiments. Hence, a numerical analyses model with FEM that is able to cover a wide range of welding speeds considering precise thermal boundary conditions was developed in this study.

The commercial software DEFORM-3D was used for the FEM simulation, and Lagrangian-code was employed for the analyses. The workpiece was set to a continuum model of $70 \times 70 \times 4 \mathrm{~mm}$ with meshing into about 32 thousand tetrahedral elements. The element sizes around the tool/workpiece interfaces were set to be about $0.1-0.3 \mathrm{~mm}$ in length, finer than those in the surroundings. The tool in this model had the same geometries as that used in experiments except that the probe height was $3.6 \mathrm{~mm}$. That is, the probe height was $0.2 \mathrm{~mm}$ smaller in the FEM simulation than in experiments and mesh breaking at model's bottom while re-meshing was avoided by an increase in the clearance between the tool tip and workpiece bottom. The probe part of the model was a cylinder pin without threads, giving priority to analysis stability during FSW simulations. There were 15 thousand tool elements, and tool/workpiece interface elements were set to be finer like the workpiece modeling. The workpiece model had a rigid plastic body and tool model a rigid body, and thermo-coupled viscous-plastic analyses were conducted.

Figure 3 represents the flow stress of aluminum alloy 6061-T6 used for the FEM analyses. This flow stress model includes not only thermal softening showing a dramatic decrease in flow stress at high temperatures but also strain ratehardening. First, quasi-static compression tests for 6061-T6 aluminum alloy were conducted under three different temperature conditions of room temperature (about $20^{\circ} \mathrm{C}$ ), $100^{\circ} \mathrm{C}$ and $200^{\circ} \mathrm{C}$ to obtain the stress-strain relationship. The geometry of a cylinder specimen was $10 \mathrm{~mm}$ in diameter and $10 \mathrm{~mm}$ in height. The stroke speed was set to $1 \mathrm{~mm} / \mathrm{min}$ for quasi-static condition. The stress-strain relationships over $200^{\circ} \mathrm{C}$ were based on references [12] [13]. Figure 4 represents the relationships between temperature and $0.2 \%$ yield strength at a strain rate of $0.002 \mathrm{~s}^{-1}$ rearranged from Figure 3. The strain rate dependence in the model can follow Johnson and Cook constitutive model shown in Equation (1), and its strain rate parameter $\mathrm{C}$ was set to 0.02 [14] to design the temperature and strain rate-dependent flow stress model.

$$
\sigma=\left[A+B \varepsilon^{n}\right]\left[1+C \ln \dot{\varepsilon}^{*}\right]\left[1-T^{* m}\right]
$$




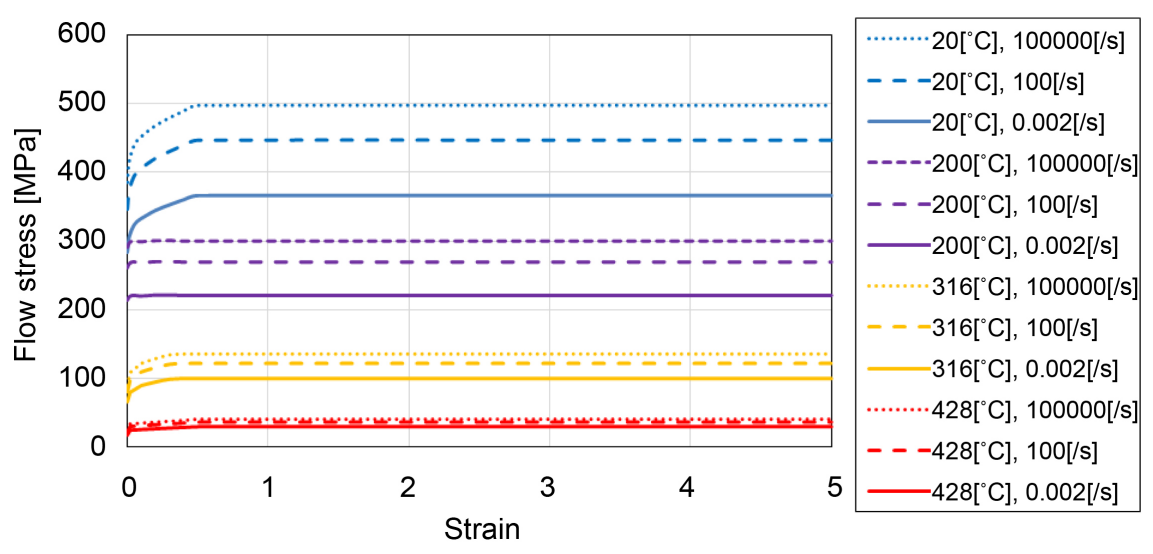

Figure 3. Flow stress model of aluminum alloy 6061 -T6 for temperatures of $20^{\circ} \mathrm{C}, 200^{\circ} \mathrm{C}$, $316^{\circ} \mathrm{C}$ and $428^{\circ} \mathrm{C}$ and strain rates of $0.002 \mathrm{~s}^{-1}, 100 \mathrm{~s}^{-1}$ and $100,000 \mathrm{~s}^{-1}$.

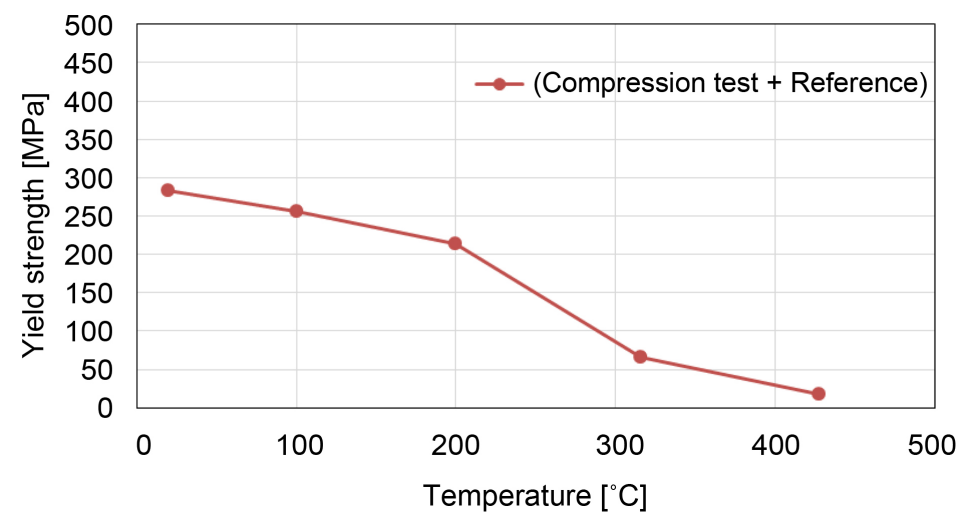

Figure 4. Relationship between temperature and $0.2 \%$ yield strength of 6061-T6 obtained from compression test results and literature values at strain rate of $0.002 \mathrm{~s}^{-1}$.

$A$ : yield stress, $B$ : strain hardening constant, $\varepsilon$ : equivalent plastic strain, $n$ : hardening exponent, $C$ : strain rate constant, $\dot{\varepsilon}^{*}$ : dimensionless strain rate, $T^{*}$ : homologous temperature, $\mathrm{m}$ : temperature exponent.

\subsection{Optimization of Thermal Boundary Condition}

A system of FSW process model includes several thermal boundaries in itself. A thermal boundary within the system is at the tool/workpiece interface, where the heat flowing between them remains inside the system itself. As for thermal boundaries against the exterior of the system, there are heat convections from the tool surface and the workpiece-top surface to the air, and heat conductions from the workpiece-bottom surface to the back plate. The amount of heat transfer from a solid body to the air is relatively small. In contrast, the heat transfer between two solid bodies in contact is not negligibly large when there are large temperature differences between them. For this reason, the heat transfer coefficient between them has a large influence on the amount of heat removed from the system and corresponding temperature reduction. Therefore, its value could 
be sensitive to analysis results, so that the heat transfer coefficient between the workpiece bottom and back plate was optimized in this research. Table 2 shows the thermal boundary conditions used for modeling.

The optimization of the workpiece-bottom heat transfer coefficient for the FEM analysis model was carried out by comparing temperatures numerically and experimentally obtained. The traverse speed and the tool rotation speed were set to $5 \mathrm{~mm} / \mathrm{s}$ and $1000 \mathrm{~min}^{-1}$, respectively. Five different values of the heat transfer coefficient at the workpiece bottom surface were set between 1.0 to 5.0 $\mathrm{kW} / \mathrm{m}^{2} / \mathrm{K}$ for optimization. For modeling a convective heat transfer as the thermal boundary condition, Equation (2) was used.

$$
q=h \times\left(T_{w}-T_{f}\right)
$$

$q$ : heat flux, $h$ : heat transfer coefficient, $T_{w}$ objectl surface temperature,

$T_{f}$ :ambient temperature or object 2 temperature.

The constraint condition of the workpiece was that the bottom surface of the workpiece was in contact with the back plate without friction and the side surfaces are fixed in all directions. Workpiece and tool surfaces conduct heat transfer against the air of ambient temperature $20^{\circ} \mathrm{C}$. The friction model between the tool and workpiece was followed by a shear friction model shown in Equation (3), and the frictional coefficient $m=1.0$ was employed [15].

$$
\tau=m \times k
$$

$\tau$ : shear stress, $m$ : friction coefficient, $k$ : shear yield stress.

After the heat transfer coefficient was optimized for the workpiece bottom surface at a traverse speed of $5 \mathrm{~mm} / \mathrm{s}$, the validation analyses were carried out at different traverse speeds to compare the analysis and experiment results of tool temperatures and traverse force.

\section{Results}

\subsection{Tool Temperature and Welding Force Measurement Results}

Figures 5-8 represent the data profile of tool temperature histories while welding at traverse speeds of $1,5,10$ and $20 \mathrm{~mm} / \mathrm{s}$, respectively. The tool rotational speeds were $1000 \mathrm{~min}^{-1}$. In each graph, temp1 is the temperature at the probe tip, temp2 at the probe root and temp3 at the tool shoulder. Each graph also indicates the welding forces of the axial and traverse directions. It should be noted that no defect was visually detected for the above four welding conditions.

Table 2. Boundary conditions used for analysis model.

\begin{tabular}{cc}
\hline & Heat transfer coefficient $\left[\mathrm{kW} / \mathrm{m}^{2} / \mathrm{K}\right]$ \\
\hline Workpiece bottom (to back-plate) & $1,2,3,4,5$ \\
Workpiece top-surface & 0.01 \\
Tool/workpiece interface & 5 \\
Tool surface & 1
\end{tabular}




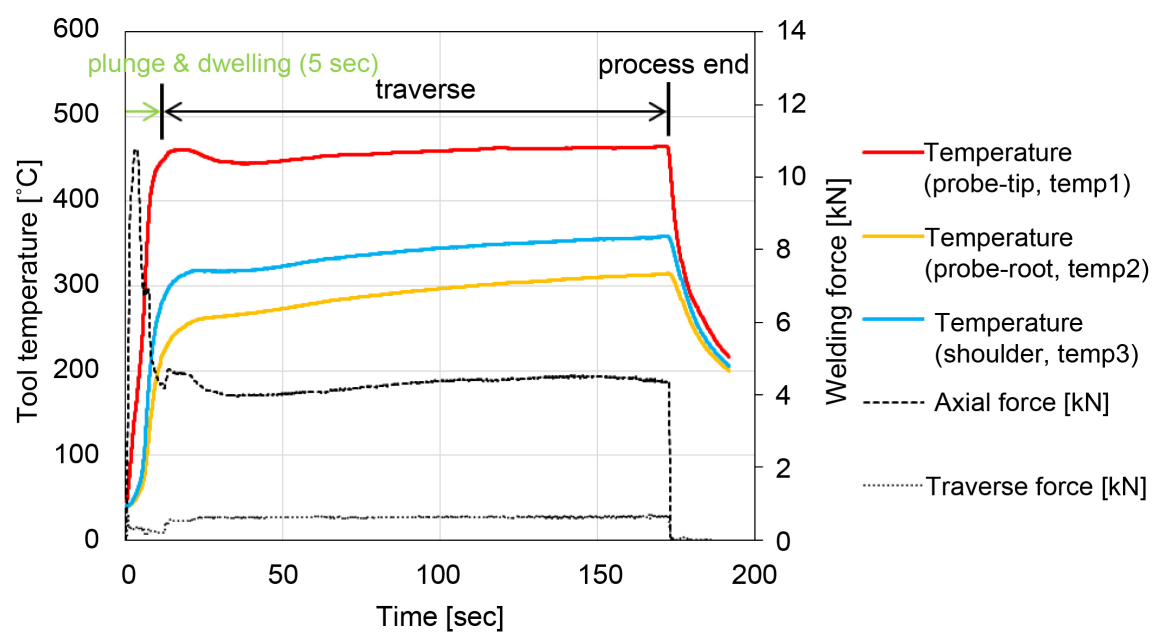

Figure 5. Data profile of tool temperatures and welding forces $\left(1000 \mathrm{~min}^{-1}, 1 \mathrm{~mm} / \mathrm{s}\right)$.

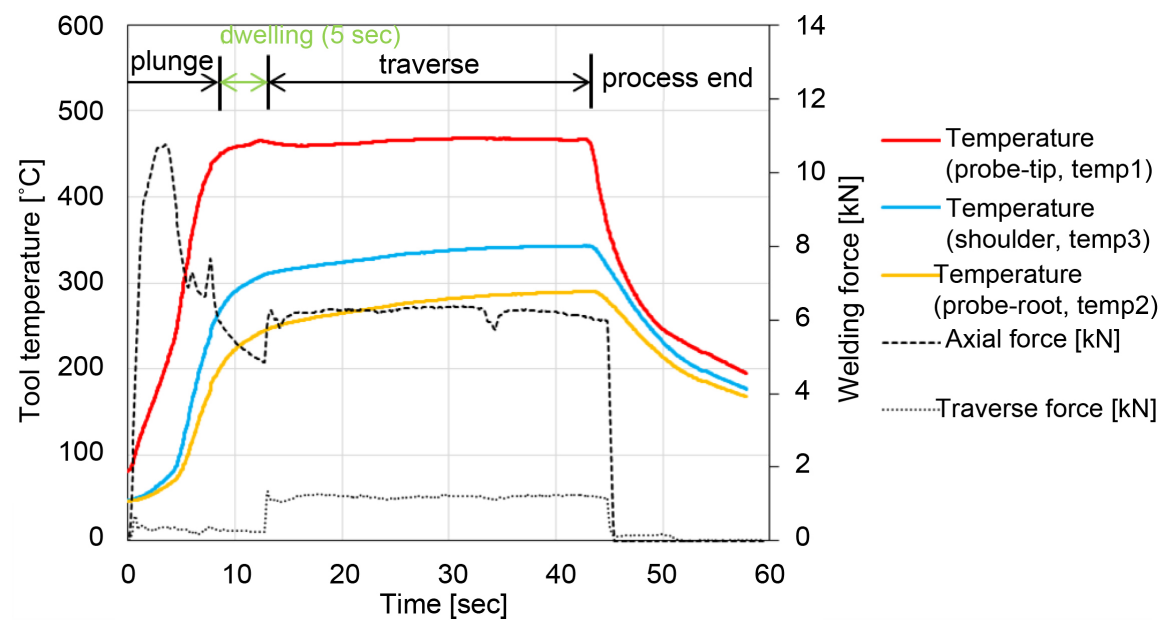

Figure 6. Data profile of tool temperatures and welding forces $\left(1000 \mathrm{~min}^{-1}, 5 \mathrm{~mm} / \mathrm{s}\right)$.

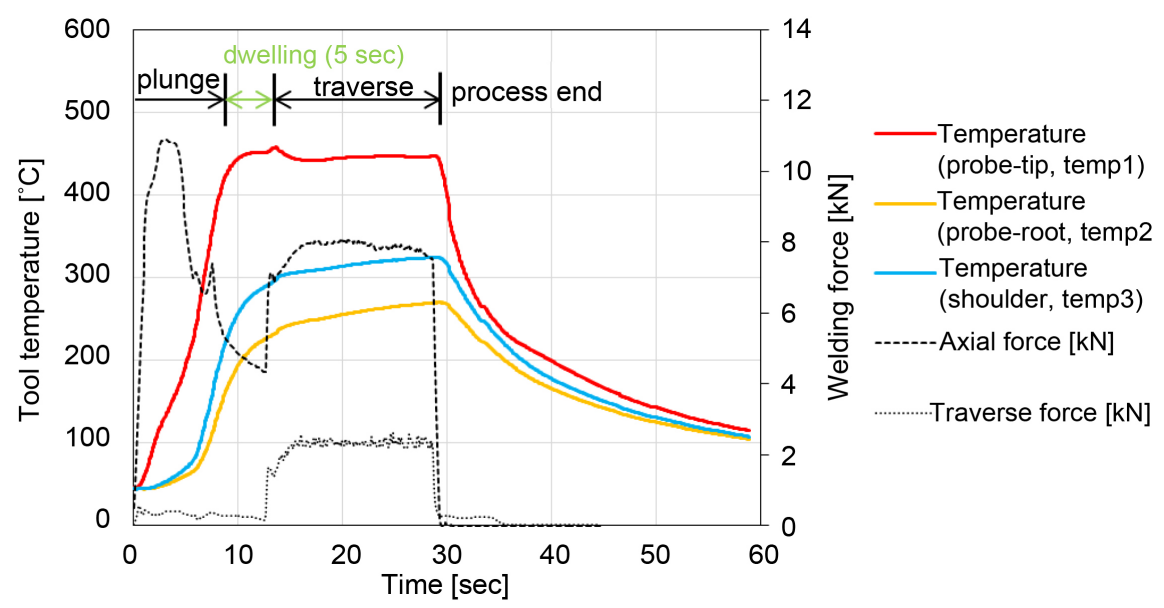

Figure 7. Data profile of tool temperatures and welding forces $\left(1000 \mathrm{~min}^{-1}, 10 \mathrm{~mm} / \mathrm{s}\right)$.

The above results confirmed that temperatures of each portion increased monotonously from the tool plunge stage to the dwelling (rotation holding) 


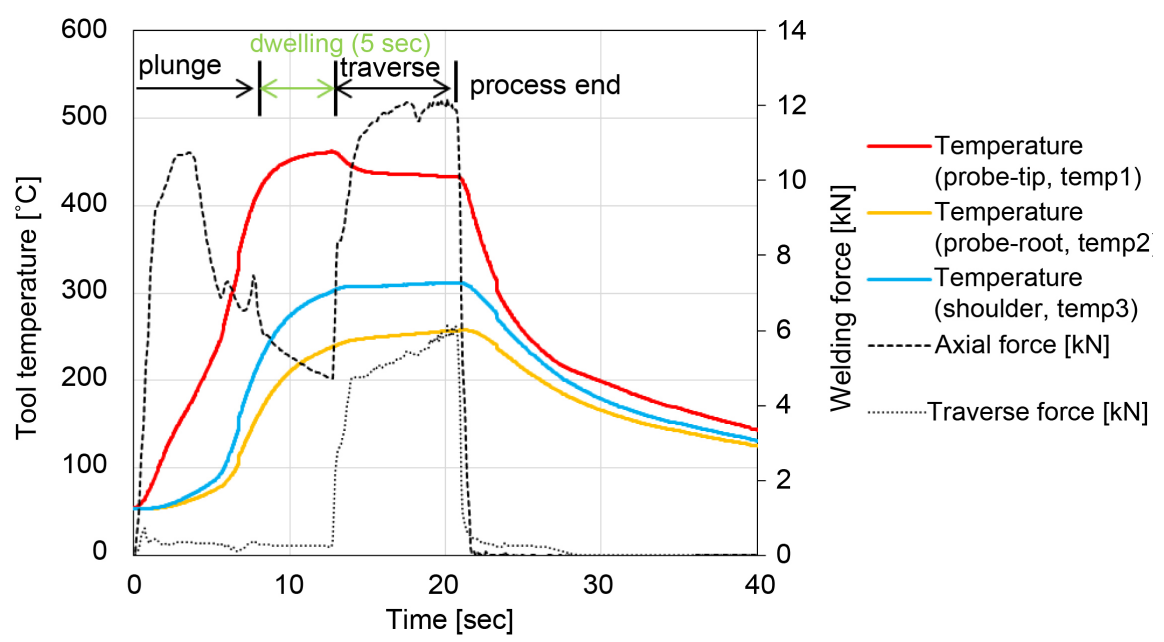

Figure 8. Data profile of tool temperatures and welding forces $\left(1000 \mathrm{~min}^{-1}, 20 \mathrm{~mm} / \mathrm{s}\right)$.

stage. Here, traversing began after a 5-second tool rotation hold. After the traverse began, probe tip temperatures (temp1) became almost constant and this steady state continued until all processes finished. On the other hand, the temperatures of the probe root (temp2) and tool shoulder (temp3) increased continuously, but slightly throughout the traverse process. Generally, the measured temperatures of tool tips were about $100^{\circ} \mathrm{C}$ to $150^{\circ} \mathrm{C}$ higher than those of tool shoulders.

As for welding forces, they were almost constant during the traverse process at traverse speeds of 1, 5 and $10 \mathrm{~mm} / \mathrm{s}$, but at a traverse speed of $20 \mathrm{~mm} / \mathrm{s}$ they kept increasing until the process finished.

Figure 9 shows the relationship between tool traverse speeds and tool temperatures. The results showed that probe tip temperatures were about $100^{\circ} \mathrm{C}$ $120^{\circ} \mathrm{C}$ higher than shoulder temperature, and about $160^{\circ} \mathrm{C}-180^{\circ} \mathrm{C}$ higher than probe root temperature. It was indicated that tool temperature at each measurement portion decreased by about $30^{\circ} \mathrm{C}$ to $50^{\circ} \mathrm{C}$ with an increase in tool traverse speed from 1 to $20 \mathrm{~mm} / \mathrm{s}$. In contrast, Assidi et al. [5] reported that tool temperatures were almost constant and nearly independent of traverse speed in a range of low tool traverse speeds from 1 to $3 \mathrm{~mm} / \mathrm{s}$. The plastic work and friction work consumed near the tool and at the tool/workpiece interface respectively can be regarded as a kind of moving heat source in high-speed welding. Because the convective heat transfer from the tool to moving workpiece increased with traverse speed, the tool temperature would decrease with increasing traverse speed.

Figure 10 shows the relationship between tool rotation speeds and tool temperatures for a traverse speed of $5 \mathrm{~mm} / \mathrm{s}$. Tool temperature increased with tool rotational speed. The probe tip temperature increased up to about $500^{\circ} \mathrm{C}$, close to the workpiece solidus temperature $582^{\circ} \mathrm{C}$. On the other hands, shoulder temperature and probe root temperature were likely to converge to about $370^{\circ} \mathrm{C}$ and $300^{\circ} \mathrm{C}$, respectively at high tool rotational speeds. 


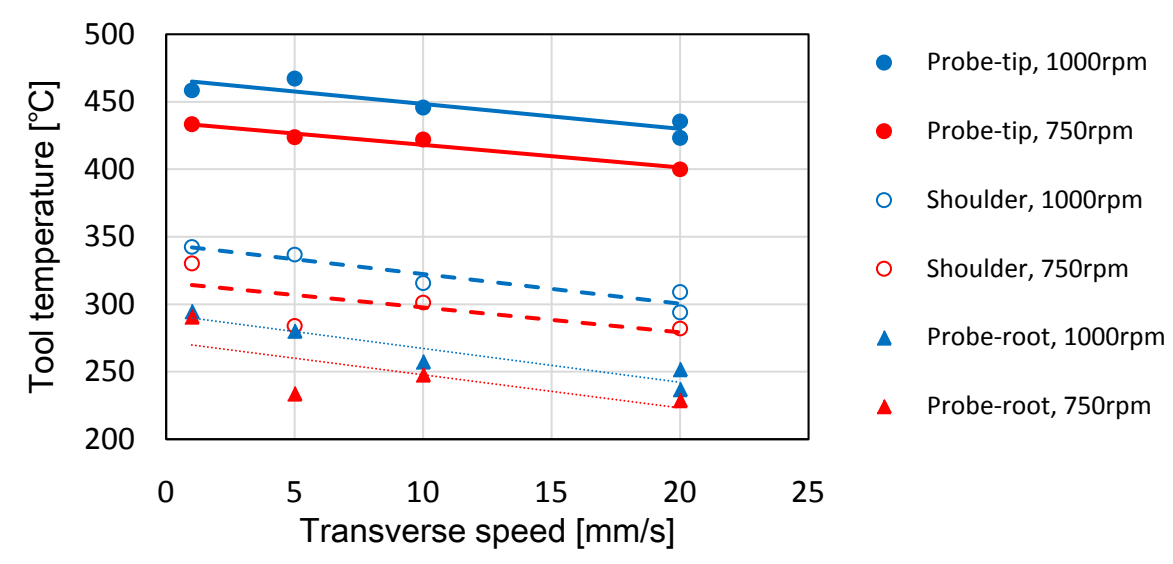

Figure 9. Tool temperatures and tool traverse speeds (rotation: 1000 and $750 \mathrm{~min}^{-1}$ ).

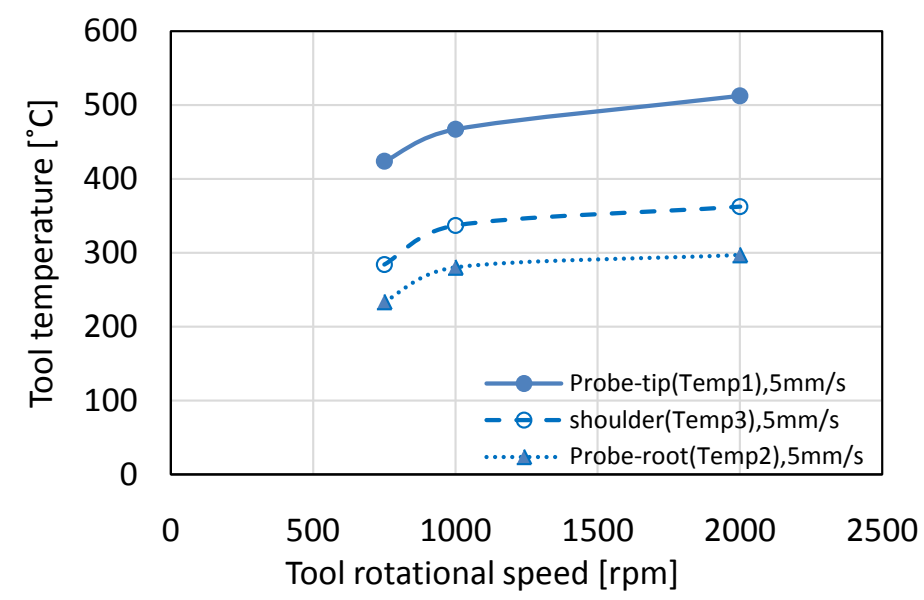

Figure 10. Tool temperatures and tool rotational speeds (at traverse speed of $5 \mathrm{~mm} / \mathrm{s}$ ).

Figure 11 shows the results of the force measurements. Each value represents the data in the middle of welding path. It was clearly seen that the welding forces increased linearly with traverse speed. These characteristics were the same as those reported for aluminum alloy 2024-T3 [11] [16] [17] [18].

\subsection{FEM Model Optimization Result}

Figure 12 shows analysis and experiment results for the tool-tip and shoulder temperatures and the welding forces in the traverse direction. Welding conditions were a traverse speed of $5 \mathrm{~mm} / \mathrm{s}$ and rotational speed of $1000 \mathrm{~min}^{-1}$ for both analyses and experiment, and data 1.0 second after traversing were compared in the figure.

In the experiment result, the tool-tip temperature was $462^{\circ} \mathrm{C}$, the shoulder temperature $313^{\circ} \mathrm{C}$ and the traverse force $1113 \mathrm{~N}$. As for the analysis results calculated for five different heat transfer coefficients, tool-tip temperature decreased by $67^{\circ} \mathrm{C}$ with increasing heat transfer coefficient from 1.0 to $5.0 \mathrm{~kW} /$ $\mathrm{m}^{2} / \mathrm{K}$. On the other hand, the shoulder temperature changed little with heat transfer coefficient. These suggest that the amount of heat flows from workpiece 


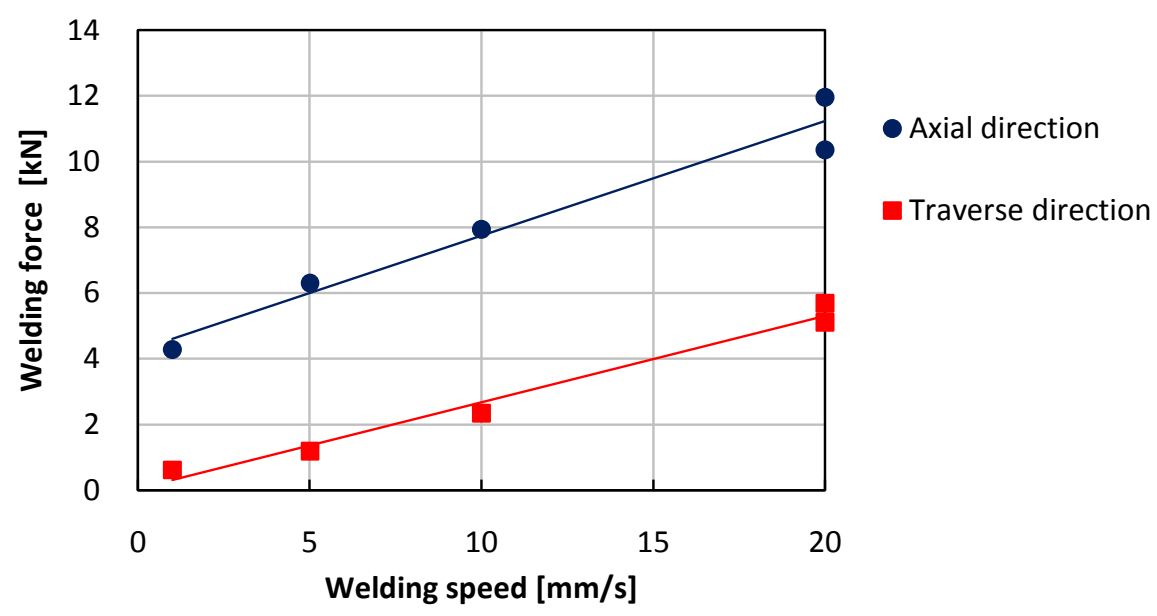

Figure 11. Welding force measurement results.

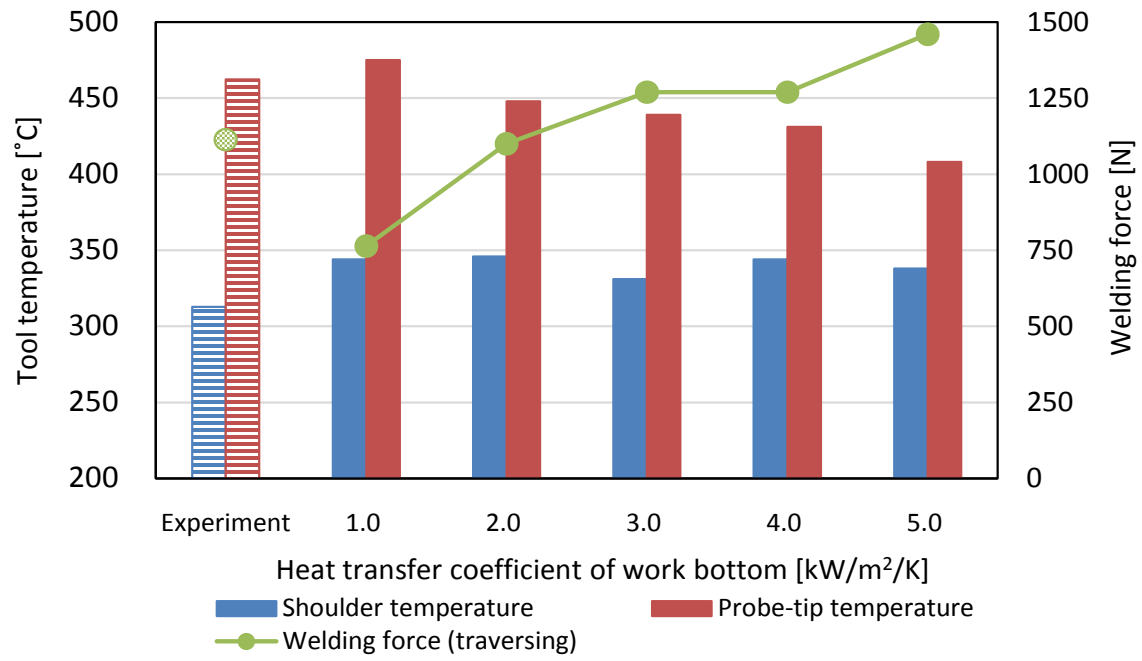

Figure 12. Experiment and analysis results for optimizing heat transfer coefficient.

bottoms to the back plate affects tool-tip temperatures sensitively since the tool-tip is close to the workpiece bottom. In contrast, the traverse force increased with heat transfer coefficient. This is because the material flow stress increased with decreasing tool tip temperature.

Figure 13 shows the error ratios between the analysis and experiment results for five values of heat transfer coefficient. The error ratio was defined by Equation (4),

$$
\text { Error }=\left|\frac{T_{t, a}-T_{t, m}}{T_{t, m}}\right|+\left|\frac{T_{s, a}-T_{s, m}}{T_{s, m}}\right|+\left|\frac{F_{t, a}-F_{t, m}}{F_{t, m}}\right|
$$

where $T_{t, a}$ and $T_{t, m}$ are tool tip temperatures analyzed and measured, respectively, $T_{s, a}$ and $T_{s, m}$ are shoulder temperatures analyzed and measured, respectively, and $F_{t, a}$ and $F_{t, m}$ are traverse forces analyzed and measured, respectively. The error ratio was the minimum at $2.0 \mathrm{~kW} / \mathrm{m}^{2} / \mathrm{K}$, the optimum value of heat transfer coefficient. It was also confirmed from Figure 12 that analysis results showed 


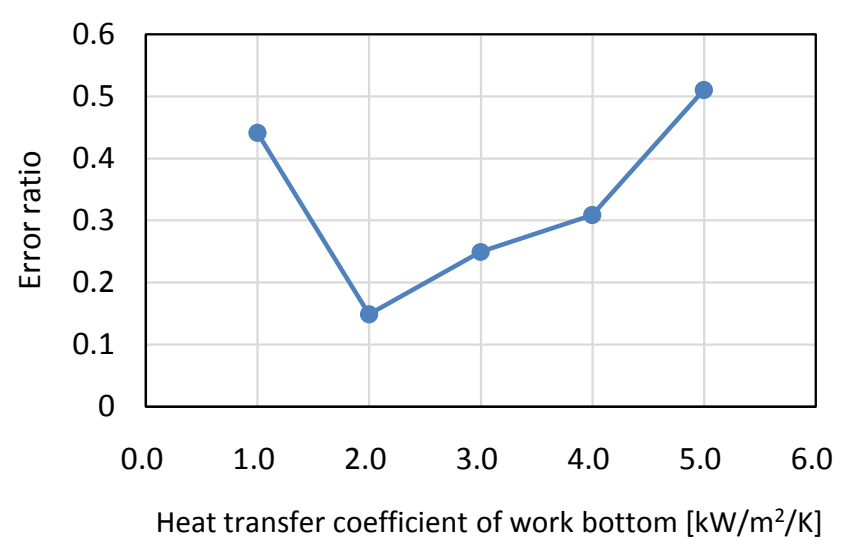

Figure 13. Difference between analysis and experiment results.

the best agreement with the experiment ones for a heat transfer coefficient of 2.0 $\mathrm{kW} / \mathrm{m}^{2} / \mathrm{K}$.

This optimization process suggests that workpiece-bottom thermal boundary conditions remarkably affect tool-tip temperatures and welding forces, i.e. material inner flow stress. The optimized value of heat transfer coefficient for the workpiece bottom obtained in this study was quite different from values of 0.2 $\mathrm{kW} / \mathrm{m}^{2} / \mathrm{K}[15]$ and $11 \mathrm{~kW} / \mathrm{m}^{2} / \mathrm{K}$ [19] used in other studies. This indicates that the heat transfer coefficient may differ under different experiment settings, so that its value is needed to be optimized for each condition. Slight differences of heat transfer coefficients affected the analysis results of tool temperatures and traverse force. This also indicates that the thermal boundary condition differences while actual welding may affect workpiece and tool internal mechanical phenomena. These suggest that, in actual FSW processes, optimum welding settings are to be determined by considering not only tool rotational and traverse speeds but also heat flows from the workpiece-bottom to the back-plate.

\subsection{Validation Result}

Validation was conducted with the developed analysis model for a low traverse speed of $1 \mathrm{~mm} / \mathrm{s}$ to a high speed of $20 \mathrm{~mm} / \mathrm{s}$, comparing the analysis data with experiment results. Figure 14 shows the validation result for tool temperatures, and Figure 15 shows for the welding forces. Both experiment and FEM data were acquired 1.0 second after the start of tool traversing. The tool-tip temperatures were almost the same between the experiment and analysis results. The shoulder temperatures of analyses and experiments had the same tendency with the traverse speed, though the analysis results became about $30^{\circ} \mathrm{C}$ to $40^{\circ} \mathrm{C}$ higher than the experiment ones. The analysis results of traverse force had good agreement with the experiment results. Then, the developed analysis model is able to simulate FSW process at a wide range of tool traverse speeds. This validation indicated that developing a FSW analysis model that calculate reasonable tool temperatures and process parameters needs accuracy of its thermal boundary conditions, especially heat transfer coefficient at the workpiece bottom. 


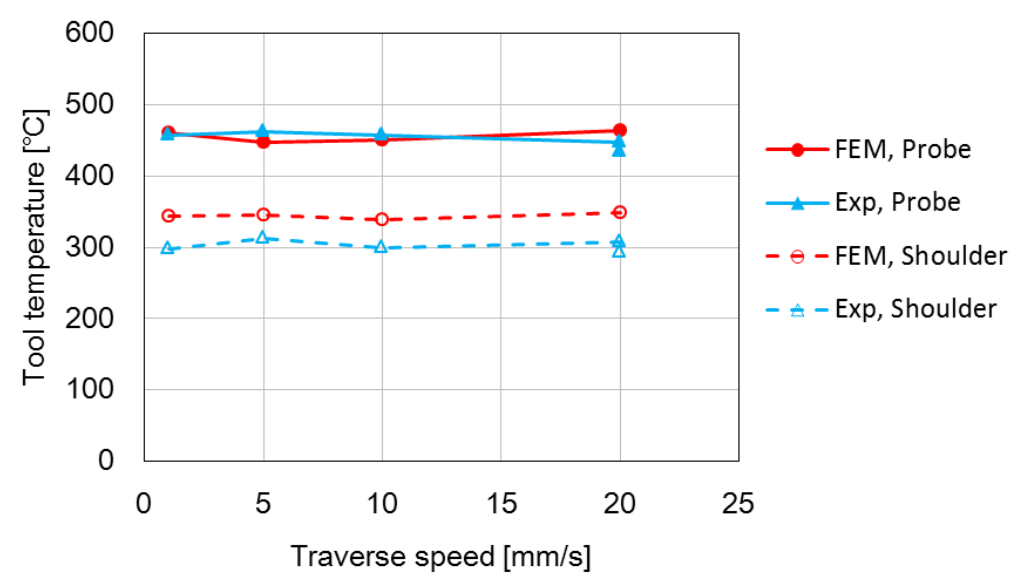

Figure 14. Validation analysis result for tool temperature.

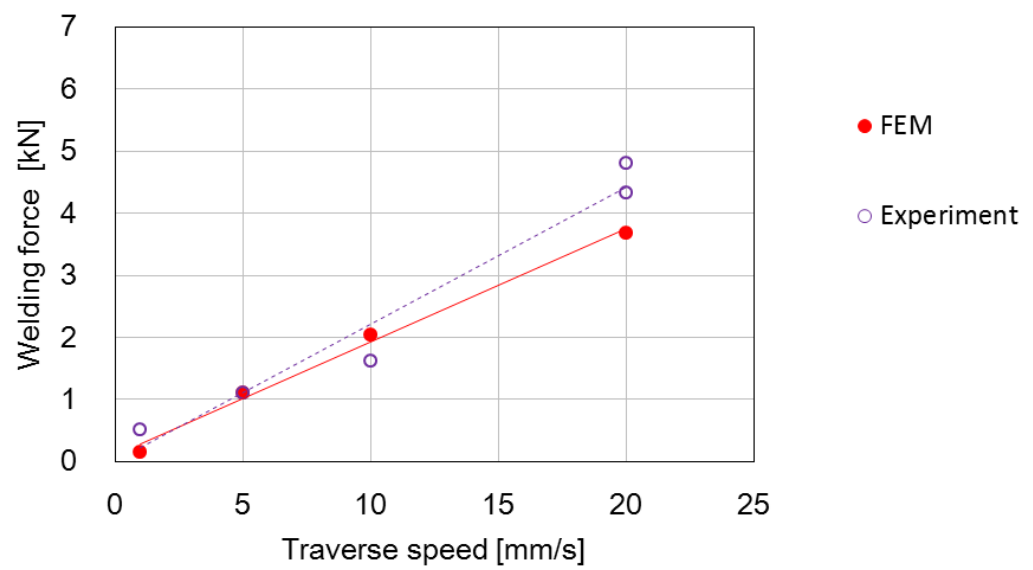

Figure 15. Validation analysis result for traverse direction welding force.

\section{Discussion}

Internal thermal-mechanical phenomena around the tool/workpiece interface were investigated with the developed analysis model. The analyses for a low traverse speed of $5 \mathrm{~mm} / \mathrm{s}$ and a high speed of $20 \mathrm{~mm} / \mathrm{s}$ were performed to investigate the temperatures and stress distributions around the tool/workpiece interfaces. Figure 16 and Figure 17 show the results of $5 \mathrm{~mm} / \mathrm{s}$, and Figure 18 and Figure 19 the results of $20 \mathrm{~mm} / \mathrm{s}$. The tool rotational speed was fixed to 1000 $\mathrm{min}^{-1}$. Each figure represents values on a cross-section of tool and workpiece along welding line.

Figure 16 and Figure 18 show that temperature inside the probe was around $440^{\circ} \mathrm{C}$ at the center of the tip surface and $400^{\circ} \mathrm{C}$ at the probe root. Calculated temperature distribution proved that the measured temperature of temp1 is almost the same as temperature at the center of tip surface. On the other hand, the shoulder had a steep temperature gradient along the tool axis, and thus, the temperatures of temp 2 and temp 3 corresponding to the measurement points inside the shoulder $1.1 \mathrm{~mm}$ from the surface were different from the shoulder surface temperatures by about $40^{\circ} \mathrm{C}$ to $50^{\circ} \mathrm{C}$. It should be noted that the shoulder 


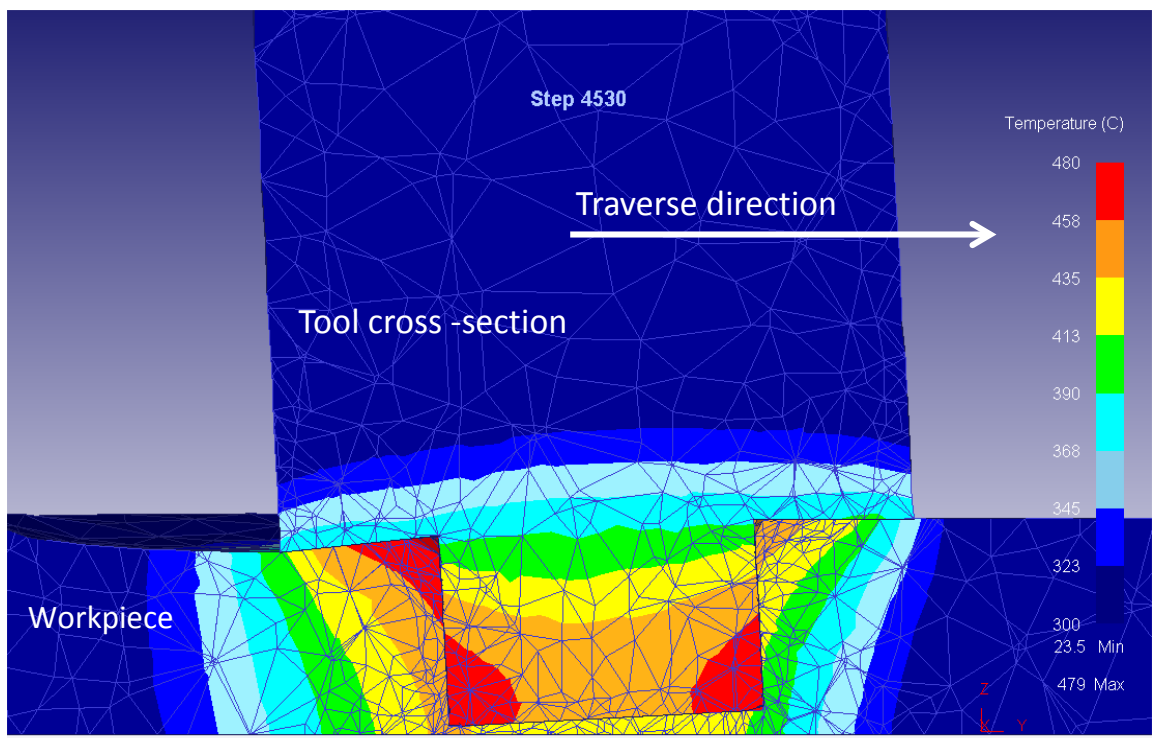

Figure 16. Cross-section showing temperatures (traverse: $5 \mathrm{~mm} / \mathrm{s}$, rotation: $1000 \mathrm{~min}^{-1}$ ).

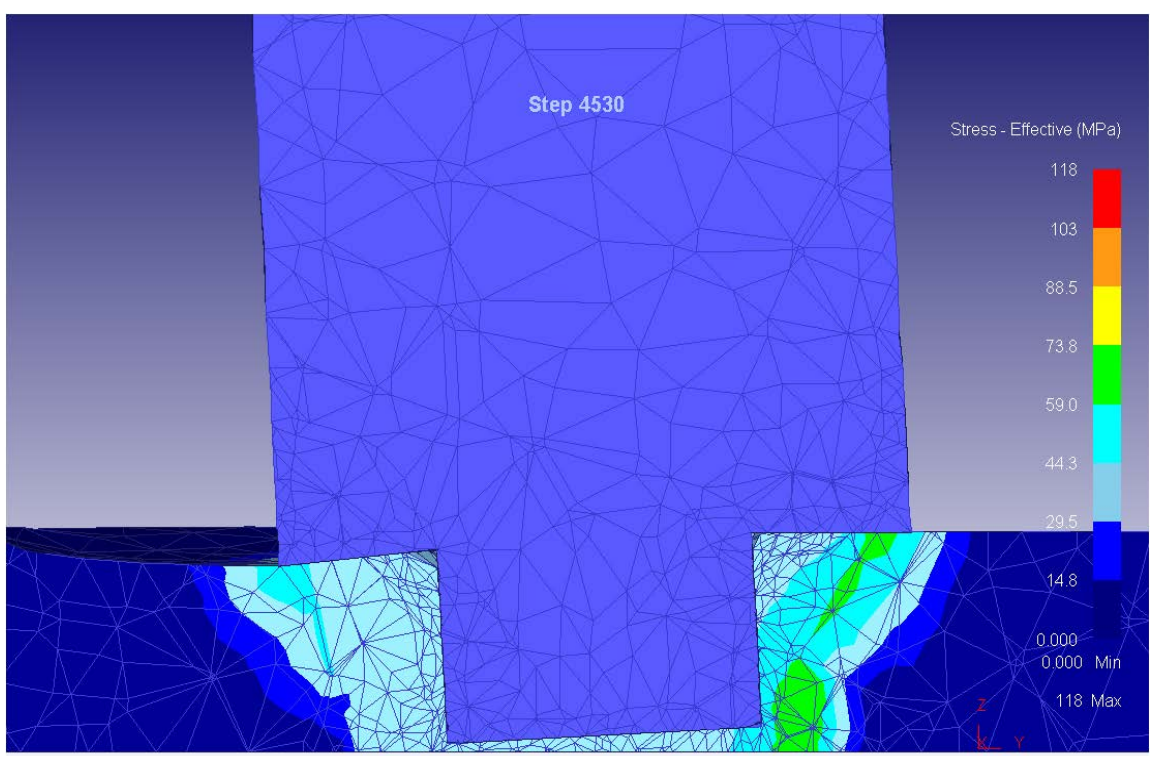

Figure 17. Cross-section showing stresses (traverse: $5 \mathrm{~mm} / \mathrm{s}$, rotation: $1000 \mathrm{~min}^{-1}$ ).

surface temperatures are higher than temperatures measured with thermocouples.

With regard to workpiece inner temperatures comparing the traverse speed of 5 and $20 \mathrm{~mm} / \mathrm{s}$, the tool front temperature distributions were definitely different, showing that the temperature was lower for $20 \mathrm{~mm} / \mathrm{s}$ than for $5 \mathrm{~mm} / \mathrm{s}$. This is because cold workpiece rapidly come close to the tool at higher traverse speed before sufficient temperature increase by plastic and friction work. As for the tool front stresses, the maximum stress was about $70 \mathrm{MPa}$ at $5 \mathrm{~mm} / \mathrm{s}$, whilst it exceeded $110 \mathrm{MPa}$ at $20 \mathrm{~mm} / \mathrm{s}$. For this reason, a zone of higher stress appeared in front of the tool at $20 \mathrm{~mm} / \mathrm{s}$, showing that the flow stress of aluminum alloy 6061-T6 is critically temperature-dependent. 


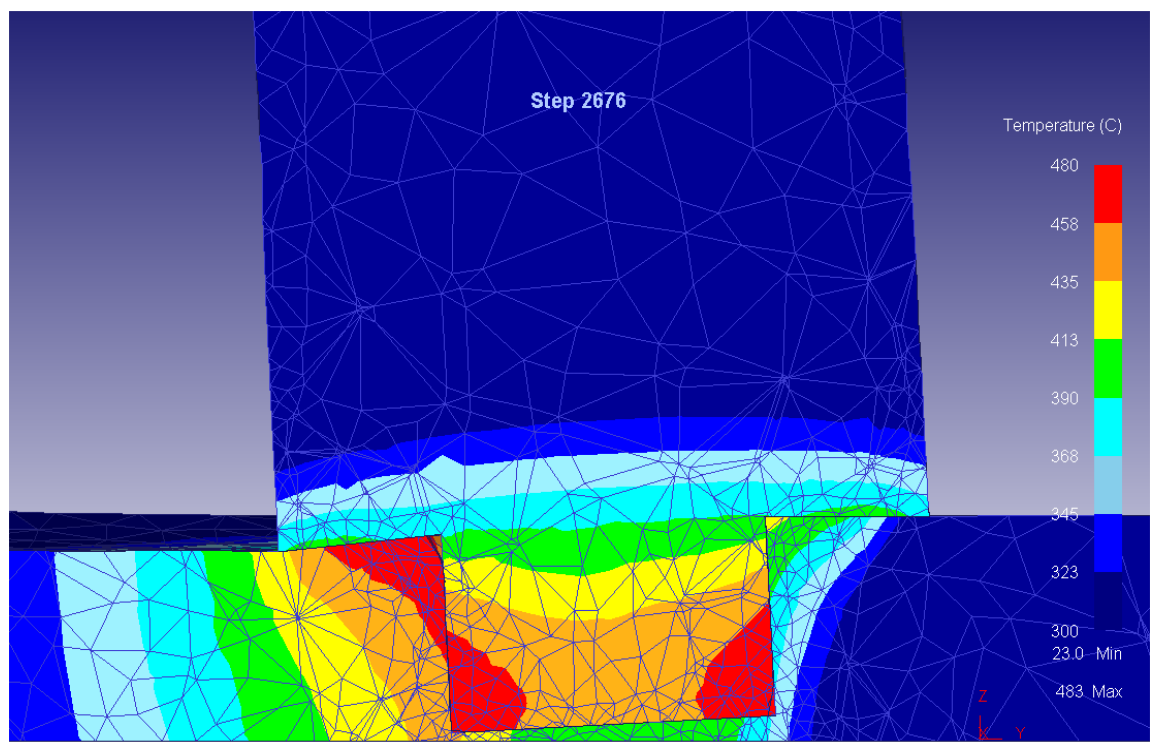

Figure 18. Cross-section showing temperatures (traverse: $20 \mathrm{~mm} / \mathrm{s}$, rotation: $1000 \mathrm{~min}^{-1}$ ).

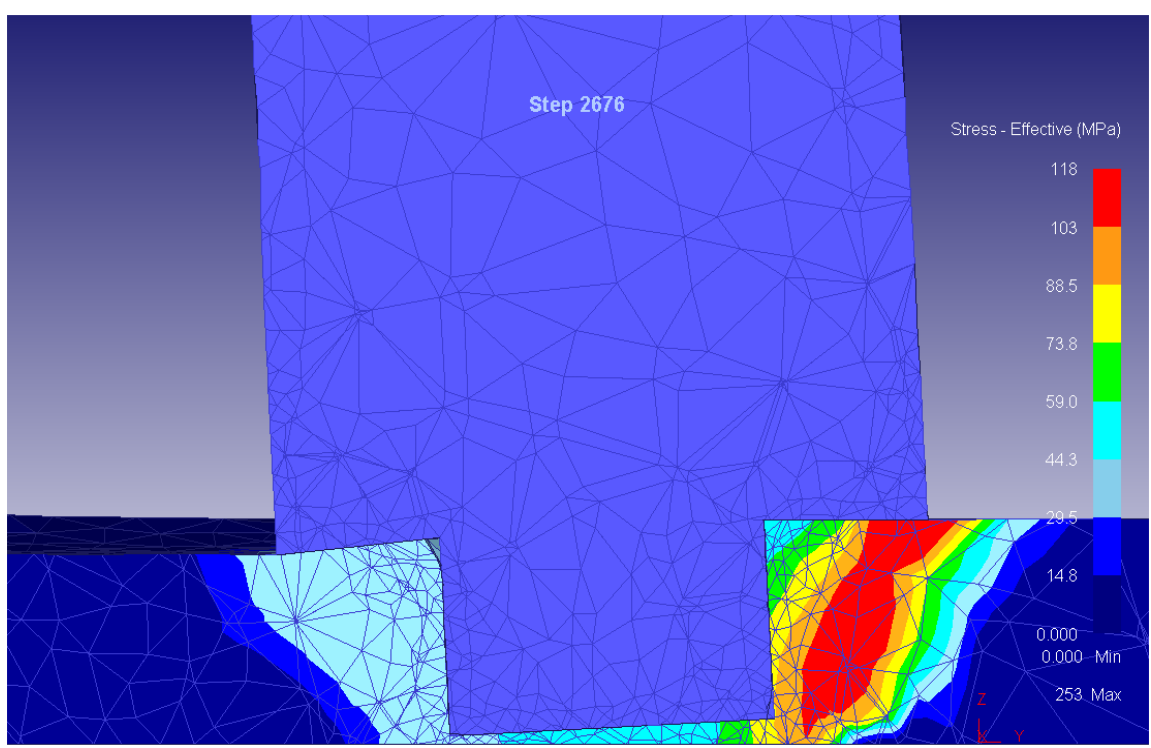

Figure 19. Cross-section showing stresses (traverse: $20 \mathrm{~mm} / \mathrm{s}$, rotation: $1000 \mathrm{~min}^{-1}$ ).

\section{Conclusions}

Tool temperatures were measured during FSW, and a thermal boundary condition was optimized with these experiment results to develop an analysis model. The following was learned through this study:

1) The heat transfer coefficient of workpiece bottom was optimized to $h=2.0$ $\mathrm{kW} / \mathrm{m}^{2} / \mathrm{K}$. Slight differences of heat transfer coefficients affected the analysis results for tool temperatures and traverse force, indicating thermal boundary conditions while actual welding may affect the workpiece and tool internal mechanical phenomena.

2) The analysis modeling considered with an optimum value of workpiecebottom heat transfer coefficient led to the reasonable model that can analyze 
FSW phenomena through a wide range of tool traverse speeds.

3) Analysis results with the developed model show that temperature inside the probe was around $440^{\circ} \mathrm{C}$ at the center of the top surface and $400^{\circ} \mathrm{C}$ at the probe root. Calculated temperature distribution proved that the measured temperature with the thermocouple at the probe tip is almost the same as the surface temperature. On the other hand, the shoulder had a steep temperature gradient along the tool axis, and thus the measured temperatures inside the tool were different from the surface temperatures by about $40^{\circ} \mathrm{C}$ to $50^{\circ} \mathrm{C}$. It showed that the shoulder surface temperatures are higher than temperatures measured with thermocouples.

\section{Acknowledgements}

The authors are grateful to YAMAMOTO METAL TECHNOS CO., LTD. for technical support with measurements and tool precision machining.

\section{References}

[1] Thomas, W.M., Nicholas, E.D., Needham, J.C., Murch, M.G., Temple-Smith, P. and Dawes, C.J. (1995) Friction Stir Butt Welding. GB Patent Application No. 9125978, 1991; US Patent No. 5460317.

[2] Rahul, J., Kanchan, K., Ram, K.K., Sachin, K., Surjya, K.P., Shiv, B.S., Sushanta, K.P. and Arun, K.S. (2015) Friction Stir Welding: Scope and Recent Development. Modern Manufacturing Engineering, 179-228.

[3] Mishra, R.S. and Ma, Z.Y. (2005) Friction Stir Welding and Processing. Mater Science and Engineering, R50, 1-78. https://doi.org/10.1016/j.mser.2005.07.001

[4] Shrivastava, A., Krones, M. and Pfefferkorn, F.E. (2015) Comparison of Energy Consumption and Environmental Impact of Friction Stir Welding and Gas Metal Arc Welding for Aluminum. CIRP Journal of Manufacturing Science and Technology, 9, 159-168. https://doi.org/10.1016/j.cirpj.2014.10.001

[5] Assidi, M., Fourment, L., Guerdoux, S. and Nelson, T. (2010) Friction Model for Friction Stir Welding Process Simulation: Calibrations from Welding Experiments. International Journal of Machine Tools \& Manufacture, 50, 143-155. https://doi.org/10.1016/j.ijmachtools.2009.11.008

[6] Guerdoux, S. and Fourment, L. (2009) A 3D Numerical Simulation of Different Phases of Friction Stir Welding. Modeling Simulation in Materials Science and Engineering, 17, 1-32. https://doi.org/10.1088/0965-0393/17/7/075001

[7] Mandal, S., Rice, J. and Elmustafa, A.A. (2008) Experimental and Numerical Investigation of the Plunge Stage in Friction Stir Welding. Journal of Material Processing Technology, 203, 411-419. https://doi.org/10.1016/j.jmatprotec.2007.10.067

[8] Schmale, J., Fehrenbacher, A., Shrivastava, A. and Pfefferkorn, F.E. (2016) Calibration of Dynamic Tool-Workpiece Interface Temperature Measurement during Friction Stir Welding. Measurement, 88, 331-342. https://doi.org/10.1016/j.measurement.2016.02.065

[9] Chen, S., Li, H., Lu, S., Ni, R. and Dong, J. (2016) Temperature Measurement of Bobbin Tool Friction Stir Welding. International Journal of Advanced Manufacturing Technology, 86, 337-346. https://doi.org/10.1007/s00170-015-8116-9

[10] Zhang, Z. and Zhang, H.W. (2009) Numerical Studies on the Effect of Transverse 
Speed in Friction Stir Welding. Material and Design, 30, 900-907. https://doi.org/10.1016/j.matdes.2008.05.029

[11] Jain, R., Pal, S.K. and Singh, S.B. (2016) A Study on the Variation of Forces and Temperature in a Friction Stir Welding Process: A Finite Element Approach. Journal of Manufacturing Processes, 23, 278-286. https://doi.org/10.1016/j.jmapro.2016.04.008

[12] Chen, C.M. and Kovacevic, R. (2003) Finite Element Modeling of Friction Stir Welding, Thermal and Thermos Mechanical Analysis. International Journal of Machine Tools \& Manufacture, 43, 1319-1326. https://doi.org/10.1016/S0890-6955(03)00158-5

[13] Chen, C. and Kovacevic, R. (2004) Thermomechanical Modelling and Force Analysis of Friction Stir Welding by the Finite Element Method. Journal of Mechanical Engineering Science, 509-519. https://doi.org/10.1243/095440604323052292

[14] Lesuer, D.R., Kay, G.J. and LeBlanc, M.M. (1999) Modeling Large Strain High Rate Deformation in Metals. The Biennial Tri-Laboratory Engineering Conference Modeling and Simulation, 3-5 November 2004, Pleasanton, CA.

[15] Rahul, J., Pal, S.K. and Singh, S.B. (2014) Finite Element Simulation of Temperature and Strain Distribution in Al2024 Aluminum Alloy by Friction Stir Welding. 5th International \& 26th All India Manufacturing Technology, Design and Research Conference, 12-14 December 2014, Vol. 486, 1-5.

[16] Trimble, D., Monaghan, J. and O’Donnell, G.E. (2012) Force Generation during Friction Stir Welding of AA2024-T3. CIRP Annals: Manufacturing Technology, 61, 9-12. https://doi.org/10.1016/j.cirp.2012.03.024

[17] Astarita, A., Squillace, A. and Carrino, L. (2014) Experimental Study of the Forces Acting on the Tool in the Friction-Stir Welding of AA 2024-T3. Journal of Materials Engineering and Performance, 23, 3754-3761. https://doi.org/10.1007/s11665-014-1140-3

[18] Arora, A., Mehta, M., De, A. and DebRoy, T. (2012) Load Bearing Capacity of Tool Pin during Friction Stir Welding. International Journal of Advanced Manufacturing Technology, 61, 911-920. https://doi.org/10.1007/s00170-011-3759-7

[19] Rahul, J., Surjya, K.P. and Shiv, B.S. (2016) A Study on the Variation of Forces and Temperature in a Friction Stir Welding Process: A Finite Element Approach. Journal of Manufacturing Processes, 23, 278-286. https://doi.org/10.1016/j.jmapro.2016.04.008 